\title{
ORDENAMIENTO JURÍDICO SIN EL ESTADO EN EL PUEBLO ASHÁNINKA
}

\author{
Néstor Machaca Mamani
}

\section{Resumen}

Este artículo estudia la comunidad de Cahuapanas, Puerto Bermúdez (Pasco), donde el ordenamiento jurídico se da a través de las prácticas socioculturales y políticas a nivel comunal. En lo sociocultural se da mediante la interiorización de normas y cumplimiento de valores y principios culturales, y en lo político, a nivel comunal, las obligaciones que están conectadas con el ámbito comunal y territorial. Las instancias estatales, por otra parte, se basan en el criterio del monismo jurídico, que no está al alcance sociocultural del pueblo asháninka del Pichis. Esta situación genera insatisfacción entre operadores de la justicia estatal y de las comunidades.

\section{Summary}

This article studies native the community of Cahuapanas, Puerto Bermúdez (Pasco), where the legal system is based on the political and socio-cultural practices at the Community level and, on the sociocultural level, through the process of internalization of rules and values and cultural principles, and politically, at the communal level, obligations which are related to the community and its territory. The State institutions, on the other hand, are based on the criterion of legal monism that are different from the socio-cultural scope of the Ashaninka people of the Pichis River. This situation creates dissatisfaction between the State and communities.

Palabras claves: Derecho Consuetuedinario-Derecho Positivo-diversidad culturalciudadanía diferenciada-ashaninca 
La dinámica del ordenamiento jurídico sin el Estado se pone de manifiesto a través de las prácticas socioculturales, políticas y jurídicas propias del pueblo asháninka; esto es, de los comportamientos institucionalizados en el marco de su cultura. Allí se produce todo un sistema de organización colectiva regido o direccionado por las autoridades comunales en el marco de la vida doméstica asháninka. Allí también encontramos, en el ámbito de las percepciones, adscripciones y propensiones de carácter intra sociocultural, la construcción de la imagen ideal del varón y la mujer asháninka, a través de la descendencia paralela, que va a ayudarnos a entender este proceso ${ }^{1}$.

El derecho consuetudinario es un elemento dinamizador del ordenamiento jurídico sin el Estado, y actúa como mediador y armonizador de la colectividad, siendo ineludible e imperioso, el criterio social-cultural y político. Es decir, desde las sociedades indígenas asháninkas, existen dos formas de hacer cumplir la ley. En primer lugar, aplicando el criterio cultural y social. En este marco, el asháninka como un ser colectivo sigue un conjunto de valores y principios culturales que lo obligan a ser respetuoso, humilde, solidario, colaborador, recíproco; en caso contrario, es socialmente castigado y metafóricamente no es considerado como asháninka. En segundo lugar, desde un criterio político de organización, los asháninkas, al vivir organizados en comunidades, están en la ineludible obligación de vivir según reglas bien definidas como la participación activa de la minga y faena comunal, participación activa en asuntos comunales, cuidar la imagen interna de la comunidad (basada en valores y principios propios) entre otros. Por ejemplo, cuando se determina que se tiene que hacer faena a favor del conjunto comunal, está obligado a laborar en la chacra y a participar en la limpieza de caminos. Todos los comuneros están obligados a participar activamente; caso contrario, se les impone sanciones o castigos según determine la asamblea comunal.

A continuación, desarrollamos, esta dinámica del ordenamiento jurídico sin el Estado. analizaremos la concepción de la estructura social asháninka desde un punto de vista teórico, para describir luego la funcionalidad de los órganos políticocomunales, de las instituciones y prácticas socioculturales, y de los determinantes a nivel infraestructural ligados a la familia por descendencia. Finalmente, se describirá y analizará las previsiones y vigencia del derecho consuetudinario en los ámbitos expuestos.

1 Este artículo es un extracto de la tesis del autor, de la Maestría en Estudios Amazónicos de la Universidad Nacional Mayor de San Marcos (UNMSM), titulada "La dinámica del ordenamiento jurídico con y sin el Estado en el pueblo asháninka", realizada con la comunidad nativa de Cahuapanas, del distrito de Puerto Bermúdez (Pasco), con la Fiscalía Mixta Provincial y el Juzgado de Paz correspondiente, basada en el trabajo de campo realizado entre 2013 y 2016. 


\section{La estructura social asháninka moldeada por la cultura-derecho}

La estructura de la sociedad asháninka se basa en la red de relaciones colectivas sistemáticas que vincula a sus miembros a través de las pautas culturales que se practican cotidianamente. Existe pues una disposición interna: cultura y el derecho, que organiza las relaciones y los actores (individuos, grupos, instituciones, valores) del sistema social. Dentro de la estructura sociocultural se encuentran una serie de repertorios establecidos que interrelacionan las esferas económica, jurídica, religiosa $\mathrm{y}$, en sentido amplio, ideológica (la propia cosmovisión). Todos los elementos culturales se hallan entretejidos unos a otros e impregnados en la cultura indígena dentro de una estructura social.

En esa perspectiva, la estructura social se mueve en función de un sistema de derecho y cultura: ambas nociones conciernen a fenómenos sociales. Mientras que la cultura es la configuración de ideas, creencias y patrones de comportamiento orientados a los valores, el derecho es el orden normativo e institucional de la conducta humana en sociedad inspirada en postulados de justicia y certeza jurídica. El derecho y la cultura forman, integran, dinamizan y da sentido e identidad a un pueblo o a una etnia definida históricamente (Stavenhagen \& Iturralde 1990; Krotz 2002). Condicionan su carácter en un lugar y momento dado. De ahí que cada grupo social defienda sus derechos culturales o étnicos cuando son afectados o perjudicados sus modos de vidas por cualquier intromisión externa.

Desde esta perspectiva, el derecho pasa de ser un aspecto de la vida étnica, a ser un instrumento de defensa y protección étnica, cuando su existencia o sus formas de vida son afectadas por intromisiones externas. Ciertamente "los sistemas jurídicos se encuentran inmersos en la cultura y en el poder" (Krotz (2002: 24). Por lo tanto, la vigencia de la cultura y el ejercicio del derecho son cuestiones que atañen al poder.

La cultura sin el derecho no tendría sentido de ser, porque en una cultura las sociedades se movilizan en función a un sistema de reglas bien definidas y codificadas, en función a los principios, valores y patrones culturales, que son arraigados en el trasfondo estructural. Por lo tanto, el derecho es un producto cultural y, en el fondo, ambas nociones se nutren y van de la mano. Cabe afirmar que el derecho es una manifestación cultural de la forma particular como una sociedad organiza su vida; el derecho también define en una sociedad el manejo de lo que es de todos (Sánchez Botero 2014: 148).

Visto así, el panorama de estudio de la antropología jurídica, las sociedades que viven con y sin Estado enfrentan dos visiones y formas de ver, entender y poner en praxis los derechos. Por un lado, el derecho indígena propio de los pueblos indígenas, definido a partir de su noción cultural y, por otro lado, el derecho occidental que es externo a su realidad sociocultural, en este caso el derecho positivo. Por ejemplo, el Estado a través de leyes (derecho positivo) otorga con facilidad tierras amazónicas 
a las empresas transnacionales para la explotación económica. Desde el Estado, la tierra es concebida solo como un recurso para la producción económica; mientras que, para los pueblos indígenas, la tierra no se concibe como un espacio de lucro, sino que es una entidad cultural y espiritual a la que se le debe un tratamiento especial (García Hierro 2004), de ahí que en sus territorios encontremos aún bosques muy bien conservados, mientras que donde predomina la población colona, ribereño, o se ubican caseríos ya no se encuentra muchos de estos. Parafraseando a Sahlins (1983) para las sociedades que viven en funcion al dinero, la tierra y los recursos naturales son trabajados en funcion a la eficiciencia de la produccion: cuando más se produce, es mayor la rentabilidad económica. Mientras que para los pueblos indigenas la tierra y los recursos naturales son sagrados, por lo tanto el criterio de trabajo no está orientado en funcion a la rentabilidad económica.

En ese marco, los estudios sociológicos y antropológicos han demostrado que los conflictos sociales en el territorio de los pueblos indígenas comportan el choque de visiones divergentes sobre la tierra, el territorio y las leyes. Es decir, choques entre cultura y derecho.

Conviene aclarar que al hablar de una relativa autonomía de cultura y el derecho dentro de una estructura social indígena no estamos sosteniendo que los grupos sociales son cerrados, "musealizados" y menos que requieran la conservación del pasado, o que sean anacrónicos como suele decirse desde el criterio occidental o eurocéntrico, sino que existe todo un continuo de construcción de la estructura sociocultural, a través de conocimientos o saberes acumulados a través de la historia: mitos, cuentos, cosmovisiones (Rojas Zolezzi 2014; Descola 2004). En términos hermenéuticos, esto equivale a decir a través de la cultura propiamente dicha por lo que se produce y reproduce según los acontecimientos del tiempo y la historia.

En la comunidad nativa de Cahuapanas las formas de vida y la convivencia están estructuradas por una serie de prácticas socioculturales y políticas compartidas por todos los miembros de la comunidad, así como en el aspecto sociocultural, las enseñanzas según la descendencia paralela (masculino y femenino), las relaciones sociales en función a los parientes consanguíneas y aliados, nosháninka (Rojas Zolezzi 2014); y por otro lado en las relaciones sociales prima los valores y los principios culturales. En el aspecto político la vivencia es en función a las obligaciones comunales: cumplimiento de faenas, mingas, vivir en función a los principios y valores asháninka como la solidaridad, en la justicia, el castigo a los infractores por sus malos comportamientos se da por acuerdo de la asamblea comunal; y así mismo, existen obligaciones determinadas comunalmente y que tienen que ser cumplidas sin mediar coacción, caso contrario puede ser expulsado de la comunidad. En fin, son elementos culturales que se estructuran en función a un sistema de cultura y reguladas por un sistema de derecho particular que no es escrito.

Desde la perspectiva de la estructura sociocultural, Gray (1984: 61-62) nos muestra que entre los amarakaeri se mantiene "la potencialidad de que la estructura 
de su sociedad se [da] según la forma del pensamiento, la acción del individuo o la del grupo". En esa perspectiva, menciona que "los amarakaeri comparten en su totalidad el sistema de parentesco, la creencia en lo anchiu, la estructura de sus mitos, también comparten los tabúes de asesinato, la caza de ciertas especies de animales y también necesitan distribuir la carne obtenida en la caza, los diferentes tipos de cambio". Un análisis sobre el trabajo permite dilucidar cómo la práctica individual se articula y se entreteje en función a la práctica colectiva, el parentesco y reciprocidad entre unos y otros, en función de elementos culturales o del sistema de cosmovisión étnica.

Entre los asháninkas, compartir los alimentos sea carne del monte, comidas o bebidas, es uno de los elementos culturales que están muy marcados en su convivencia. En palabras de Varese:

El hombre que no ofrenda generosamente a otro no es un individuo completamente "enculturado", es apartado tácitamente por la sociedad. El niño tiene que aprender las normas de este juego social desde sus años más tiernos, puesto que faltar a la costumbre, a la etiqueta, no respetar al huésped, no obsequiarlo con comida, no intercambiar con él generosamente, significa romper este fluido que une a los hombres, significa romper la comunión, atentar contra la misma sociedad (1973: 23).

En la comunidad de Cahuapanas la frase común es "no ser mezquino", compartir es el elemento determinante y es muy explícito en las relaciones sociales, compartir la carne del monte, ofrecer comida a los visitantes, dar alimentos cuando alguien requiere como, la yuca, pituca, plátano: toda la interacción es en forma de reciprocidad.

Precisamente, lo que hace que se mantengan las estructuras sociales es la misma dinámica de vida, el estar conectados con el mismo sentido de las cosas, el mismo pensamiento, las reglas comunes de juego, códigos y símbolos que los orientan y mantienen interconectados y vinculados entre sí. Las conexiones se dan precisamente mediante las relaciones de convivencia comunal, interdependencias o vinculación mutua; a esto contribuye la racionalidad en la lógica de reciprocidades, que consiste en la ayuda mutua entre quienes están conectados o emparentados culturalmente al interior de la comunidad. Estas redes de conexión en la práctica permiten que toda acción social sea complementaria entre quienes comparten el mismo marco cultural. Si se alteran las racionalidades que están conectadas a través de las interdependencias y lógicas de reciprocidad a nivel colectivo, en la estructura social, es posible que la sociedad se mueva al ritmo de su andar poniendo sanciones y castigos, de acuerdo con el grado de alteración experimentado, y encuentre salidas de acuerdo con el criterio cultural estructurante, en lo que se conoce como homeostasis cultural.

En principio, queda sentado que las sociedades indígenas se organizan sobre la base de una estructura de modelos de estereotipos, o a través de valores y 
principios culturales prevalecientes. $\mathrm{Y}$ a pesar de que es posible comprobar que los nuevos tiempos traen cambios, tensiones sociales y culturales que experimentan las sociedades amazónicas, sus miembros suelen persistir en prácticas culturales propias o, en algunos casos, adoptando ideas ajenas pero sujetándolos a los estilos o maneras de práctica social indígena. En algunos casos, pareciera que se consolidan los valores y principios culturales de las sociedades indígenas (Radcliff-Brown 1994: 319) nos ilustra sobre los cambios y continuidades de la estructura social, a partir de su teoría estructural funcional, que "la estructura puede cambiar, a veces gradualmente, a veces de manera repentina, como en las revoluciones y en las conquistas militares pero, incluso en los cambios más revolucionarios, se mantiene cierta continuidad de estructura".

La sociedad asháninka, como todas las sociedades indígenas, ha sido históricamente hostilizada, marginada y sometida a homogeneización. Pero aun así se mantiene en su mundo cultural; o en todo caso ha sabido indigenizar los elementos modernos o externos a su espacio sociocultural y político. De esta forma, perduran modos de vida que corresponden a culturas milenarias vivas, a pesar de los intentos de etnocidio, alienación y homogenización cultural. Es visible que estos pueblos han logrado sobrevivir hasta ahora gracias a su conciencia étnica que implica una esforzada supervivencia económica y cultural en el medio amazónico, visto contemporáneamente como botín apetecible para la voracidad de intereses económicos transnacionales.

\section{Organización, instituciones y niveles en la resolución de pleitos}

Un componente clave de la estructura organizativa comunitaria son las instituciones, ya que es a través de estas que se viabilizan las prácticas socioculturales, jurídicas y políticas. El orden de la sociedad está regulado por instituciones que son un sistema de convenciones sociales duraderas, dirigidas por una infraestructura reconocible. Entre las múltiples instituciones, suelen ser relevantes la familiar, la educativa, política, económica, jurídica, religiosa. Por su parte, las organizaciones están constituidas por grupos de personas que interactúan entre sí, en virtud de mantener relaciones sociales imperecederas con el fin de establecer equilibrio entre quienes se interrelacionan.

Vamos a centrar nuestro interés en las instituciones y órganos de las estructuras implicadas en la administración de justicia y el mantenimiento del cuerpo comunitario, mediante la dirección y conducción ejercida por autoridades legítimamente elegidas por la comunidad en función a la vida doméstica; es decir, en función de lo que dice y hace la colectividad en su conjunto. Esta metodología la hemos tomado, porque las personas dentro de una comunidad están organizadas política, jurídica y culturalmente: lo formal es explícito en las comunidades. Por lo tanto, la vivencia de una persona mucho depende del órgano comunal institucional, no hay ninguna persona que pueda vivir al margen de las reglas comunales establecidas por ellas mismas: la de ser comunero y comunera. 
Asimismo, prestaremos atención a los elementos del nivel intra-sociocultural, que tienen que ver con la construcción de la imagen ideal del varón y la mujer asháninka, a través de la descendencia paralela.

\section{Organización político-administrativa y jurídico-comunal}

La organización político-administrativa y jurídico-comunal es el rostro de identificación y comunicación ante y hacia otras comunidades, sean indígenas o no indígenas. A través de sus distintos órganos de gobierno y administración de justicia, la comunidad se vincula con organizaciones pares y con el Estado. Mientras la relación con otras comunidades colindantes es fluida, considerando que comparten similares características culturales, sociales y políticas; mientras con el Estado la relación y comunicación no es fluida; más bien es vista como algo remoto y ajeno.

Al respecto, investigaciones realizadas por Belaunde, Coronado \& otros (2005: 25) en tres pueblos indígenas awajún, asháninka y shipibo-conibo, han detallado que "hay un alto grado de distanciamiento y falta de familiaridad con la idea del Perú [...]. Estas respuestas parecen indicar que, para muchos hombres y mujeres de las tres etnias, el Perú es algo remoto y ajeno".

En el trabajo de campo cuando preguntamos a los asháninka sobre, ¿si conocían a la ciudad de Lima o alguna vez han viajado? La respuesta era siempre "ir a Lima es como ir a otro país, otra nación [...]" (Rosa López y Sandra Lucila, comunidad de Cahuapanas, mayo 2014). La capital es relacionada con la idea de otro país y otra nación. Las autoridades comunales dicen acerca de sus experiencias en relación con el Estado: "Nosotros nunca hemos dependido del Estado, siempre hemos vivido con nuestro esfuerzo. El Estado, más bien, nos ha traído problemas, nos ha quitado tierras, sus leyes no funcionan aquí, pero nos obligan que cumplamos" (Alcides Calderón, ex dirigente de la ANAP, setiembre 2015).

Es notoria la distancia y lejanía del Estado con los pueblos indígenas. Para obtener la integración y reconocimiento de sus comunidades y sus territorios, las autoridades comunales y organizaciones indígenas han tenido que luchar por décadas y siglos; y aun muchas comunidades no son reconocidas. Esto lo pudimos constatar en el XXIX Congreso Asháninka del Pichis del 2016, las comunidades no reconocidas expresaron a la Dirección Regional Agraria de Pasco (DRAP), el reconocimiento y formalización de las comunidades. Por lo tanto, el reconocimiento cabal de las comunidades nativas o pueblos indígenas aún queda pendiente.

Asimismo, las formas de organización de las comunidades han sido puestas bajo criterios occidentales. Brandt (1986) las denominaría "comunidades aculturadas"; sin embargo, lo real es que estas comunidades nativas han optado en mimetizar o adoptar estratégicamente la forma de organización social (organización comunal) bajo una dinámica cultural mixta; es decir, incorporaron y crearon un sistema nuevo, y tal vez podemos decir moderno, porque incluyeron canales de 
comunicación externos en su sistema sociocultural de un modo muy funcional. Por lo tanto, las comunidades nativas a través de la organización comunal, representados por sus autoridades comunales tienen canales de comunicación hacia el mundo exterior: Estado, ONG, empresas privadas y otros.

Al respecto, en su estudio sobre la justicia popular: nativos y campesinas, Brandt (1986) clasifica en tres etapas las formas de organización de las comunidades nativas, en función de su capacidad para resolver conflictos: 1) grupos tradicionales, segmentarios y acéfalos, 2) grupos étnicos en proceso de transformación hacia comunidades nativas y 3 ) grupos aculturados organizados en comunidades. En la primera, faltan instituciones de dominio, carecen de un poder institucionalizado y de un aparato represivo; además, el derecho consuetudinario no protege un interés colectivo y los conflictos se resuelven por la venganza, las sanciones son impuestas y ejecutadas por las mismas víctimas o sus familiares, etc. En la segunda existe un poder institucionalizado de la asamblea a los jefes de familia y al jefe o apu de la comunidad; las sanciones son impuestas para el mantenimiento de la paz social. Y, en la tercera, la estructura de poder está mucho más marcada y diferenciada.

En la comunidad de Cahuapanas, la organización comunal que es constituida formalmente, les ha permitido mayor cohesión social interna bajo la determinación cultural étnica con reglas implícita (vivir bajo los principios y valores culturales) e explícitamente definidas como las obligaciones comunales a favor del conjunto social.

En ese marco, las comunidades nativas de hoy no son aculturadas, viven en función a la dinámica de su repertorio cultural y cuentan con instituciones y organizaciones político-administrativas, así como jurídicas, en donde encontramos al jefe y su cuerpo directivo, el teniente gobernador, los delegados y la asamblea comunal.

Asimismo, para asumir los cargos comunales hay ciertos requisitos indispensables que tienen que ser tomados en cuenta por todo el conjunto comunal, tales como tener mando y carácter, pero no con un carácter autoritario, sino tener un carácter moderado y sobre todo premunido de paciencia y capacidad. En muchas de las comunidades prefieren a una persona que haya servido en el Ejército, porque según los asháninkas las personas que han servido al Ejército son bien vistas y apreciadas como personas decididas, capaces de conducir la comunidad y relacionarse con las distintas instituciones externas a la comunidad.

Sobre todo, para asumir cargos comunales, generalmente prefieren a personas que sepan leer, escribir y sepan hablar el idioma español es el primer requisito: “(...) sino sabe leer ni escribir cómo va asumir cargo y cómo va a buscar proyectos de afuera, si uno no saber leer la gente de afuera se burlaría" (Alicia Jeriama, mujer, comunidad de Cahuapanas, agosto 2016). Porque una autoridad comunal no solo 
cumple sus funciones dentro de la comunidad con su gente sino con el exterior, se relacionan con las instituciones del Estado, ONG y otros.

Asimismo, en la resolución de pleitos y conflictos, estos órganos sociopolíticos tienen mayor efectividad que el propio Estado, porque las autoridades comunales hacen efectiva la justicia sometiéndola a la masa colectiva comunal: la asamblea. Allí se determina el castigo y la sanción, sea económica (multas), castigo físico (mediante ejercicio físico) o castigo drástico físico (a través de látigo o varas, chalanka y tangarana). Así mismo, el proceso de resolución de pleitos y conflictos se operativiza por niveles de orden jerárquico. En el siguiente esquema se puede observar cómo funciona este sistema de resolución de conflictos internos.

\section{El derecho consuetudinario en sociedades pluriculturales: una aproximación desde el pueblo asháninka}

Al hablar de derecho consuetudinario en sociedades pluriculturales como en el Perú, nos referimos a que cada cultura o sociedad con modos de vida diferentes tiene sus propias concepciones y sistemas de derecho que tienen que ver con la regulación del orden y preservación del equilibro en la colectividad. De ahí que se defina el derecho consuetudinario como "un conjunto de normas legales de tipo tradicional, no escritas, ni codificadas, distinto del derecho positivo vigente en un país determinado" (Stavenhagen e Iturralde 1990: 29), y que varía según la cultura (Albó 2000).

En estos términos, el derecho consuetudinario rige en sociedades que viven sin y con el Estado con vocación colonial, a pesar de la sistemática imposición del derecho positivo. El derecho consuetudinario, en estos casos, norma las relaciones que responden a modos de vida compartidos por una colectividad específica conforme a usos y costumbres tradicionales. Este derecho sustentado en la costumbre pervive en colectividades étnicas nativas, mientras que el derecho positivo es elaborado a partir de conocimientos de la epistemología occidental, según el criterio e intereses del sistema que cautela el Estado. Al respecto, Konstantinov (1963: 170) señala:

La división de la sociedad en clases y la aparición del Estado, hicieron nacer el derecho en vez de la costumbre, las normas coactivas del comportamiento de los hombres establecidas por el Estado y que expresaban, no la voluntad del pueblo, sino la de clase económica y políticamente dominante.

En los Estados postcoloniales el derecho solo suele entenderse desde la posición derecho positivo occidental y no desde el otro derecho que se genera a partir de las relaciones sociales y prácticas culturales alternas. Con la comparación y descripción de ambas formas de derecho no se pretende teorizar de manera paralela, solo se trata de proponer un acercamiento al derecho consuetudinario, porque muchas veces es entendido como una cosa del pasado, como si no existiera o como si 
los pueblos indígenas estuvieran extintos. Es obvio que allí donde existe pluralidad étnica se acentúan las implicancias de la vinculación "cultura-derecho".

La existencia de pueblos indígenas acarrea la existencia del derecho propio o derecho no escrito. Siendo el derecho la fuerza que mueve y articula toda la dinámica cultural, ciertamente los pueblos indígenas efectivizan la justicia haciendo uso de su derecho ancestral. Aunque, por otro lado, vienen conquistando el respeto por el mismo mediante una larga lucha por su incorporación como sujetos de derechos colectivos dentro del derecho occidental y de la ciudadanía nacional. Esta lucha es una de las principales tensiones que se viven en las sociedades modernas:

[...] existe un nodo problemático que todavía no encuentra resolución al interior de los discursos multiculturales hegemónicos. Tal es la incorporación de la diversidad cultural como la incorporación de otro "real" que encarna un modo de vida sustentado en concepciones éticas y morales radicalmente distintas a las que han sido la base de la construcción de los Estados occidentales (Castillo Gallardo 2009: 13).

En consecuencia, en el siglo XXI la perspectiva del derecho colectivo en el derecho occidental no ha procesado la visión de los pueblos indígenas, sino que su visión del derecho humano proviene de la experiencia de dominio que acompaña a los Estados postcoloniales (Santos 2012).

En el caso peruano, si bien se reconoce la pluralidad étnica y lingüística en la Constitución de 1993, en la práctica este principio no se implementa en las políticas públicas del Estado -sean nacionales, regionales o locales-, a pesar del Convenio 169 de la OIT y su ratificación en el año 1994 y su re ratificación 2009. Por el contrario, en países como Bolivia y Ecuador es paradigmático el reconocimiento de los pueblos indígenas, por lo que se han hecho presentes nuevos Estados con constituciones plurinacionales.

Yrigoyen (2001) señala que, si bien la Constitución de 1993 reconoce el derecho consuetudinario, en la práctica no se implementa, porque cuando examina los centenares de proyectos presentados en el Congreso no encuentra iniciativa alguna que otorgue facultades de aplicación por las autoridades de los pueblos indígenas:

En ningún caso, se ha planteado la ampliación de materias que podrían ser conocidas por una jurisdicción especial. Cualquier intento de establecer limitaciones al derecho positivo nacional tropieza con "argumentos" que corren boca en boca en las discusiones del Congreso o las Cortes, en el supuesto de que significarían "otorgar mucho poder" a la jurisdicción especial. Hay un miedo colonial frente a la posibilidad de una presunta sublevación latente de los indios. Igualmente, los reparos parecen vincularse a la ideología de la incapacidad indígena (" ¿cómo van a resolver casos graves, si son indios?") (Yrigoyen, 2001: 136). 
Si bien encontramos en el Convenio 169 de la OIT la adopción del derecho consuetudinario, su aplicación es tomada con pinzas y muchas veces entra en contradicción con la constitución de los Estados firmantes. De igual forma, la legislación sobre derechos humanos a nivel internacional no puede parametrarse universalmente de manera tan sencilla, en cuanto la diversidad cultural ha permitido construir diferentes marcos de valoración ética.

Muchas de las constituciones de los Estados postcoloniales han sido hechas sobre la idea del colonialismo occidental, según la filosofía y los intereses de la clase criolla económica y políticamente dominante (Marés 2014). Por lo tanto, la idealidad de Estado-nación es construir una sociedad uniforme, el mestizaje como elemento determinante y modernización social (Tamayo Herrera 1998). La diversidad cultural es objeto de estereotipación, según la cual los pueblos indígenas son sociedades congeladas en el pasado. Por eso, los esfuerzos por construir el ideal de los derechos humanos universales se limitan a la idea de una ciudadanía universal dentro del parámetro de la cultura occidental (Santos 2012), sin la ciudadanía diferenciada. Un conjunto de presupuestos occidentales subyace al concepto de derechos humanos. Veamos cuáles son:

El concepto de derechos humanos se basa en un conjunto bien conocido de presupuestos, todos los cuales son claramente occidentales, a saber: hay una naturaleza humana universal que se puede conocer por medios racionales; la naturaleza humana es esencialmente distinta de, y superior a, la del resto de la realidad; el individuo tiene una dignidad absoluta e irreductible que debe ser defendida frente a la sociedad y al Estado; la autonomía del individuo requiere de una sociedad organizada de una manera no jerárquica, como una suma de individuos libres [...]. Esos presupuestos claramente occidentales y liberales, son fácilmente distinguibles de otras concepciones de la dignidad humana en otras culturas (Santos, B. 2012: 89).

Correlativamente, el derecho en el orden colonial es individualizado y se sujeta a los intereses del Estado, es decir, cada sujeto tiene su esfera de derecho y por lo tanto no puede invadir la esfera del derecho del otro. Si a un individuo se le ocurre invadir la esfera del derecho del otro, obviamente no se puede ejercer la justicia por mano propia, la violencia por sí misma no es permisible. Lo que cabe hacer es ir ante el Estado para pedir justicia.

No cabe desconocer la evolución de los derechos humanos de los pueblos indígenas en la perspectiva del derecho occidental. El mexicano Rosillo Martínez lo ha expresado claramente:

[...] primero nacieron los derechos burgueses con las revoluciones, pero después estos derechos fueron expandidos por los derechos sociales, entonces ya hablamos de primera y segunda generación, pero después vino un proceso de especificación. Entonces esos mismos derechos que primero eran de burgueses y que luego se expandieron a las 
clases obreras, campesinas o pueblos indígenas, con las revoluciones sociales se fueron especificando para atender algunos sujetos concretos que los necesitaban.

Como se ve, no se trata de una simple expansión de los derechos burgueses, es realmente una lucha de los sectores subalternos, en la cual los obreros empezaron arrancando privilegios de la burguesía acostumbrada a la libertad de contratación y renuente a reconocer los derechos sociales que significan una restricción para sus beneficios.

Con la evolución de los derechos humanos occidentales los sujetos reprimidos por la clase social dominante ya no son tocados físicamente ni esclavizados visiblemente, pero culturalmente siguen siendo vulnerados dado que los derechos humanos son concebidos desde el ángulo cultural occidental. Muchos indígenas siguen y seguirán siendo encarcelados al tener perspectivas culturales diferentes a las de la sociedad occidental:

Los pueblos no occidentales han desarrollado a lo largo del tiempo concepciones sobre la dignidad humana no sistematizadas conceptualmente en términos de derecho. [...] todas las culturas tienen versiones diferentes de la dignidad humana, algunas más amplias que otras, algunas con mayor compás de reciprocidad que otras, algunas más abiertas a otras culturas que otras (De Sousa, en Tubino, 2015: 72).

En el marco de las luchas de los pueblos indígenas, el derecho consuetudinario ha jugado un rol protagónico, porque gracias a él las sociedades o culturas subordinadas por el colonialismo han venido articulándose y, a la vez, legitimándose como culturas diferentes a la cultura occidental europea. Por lo tanto, en un contexto de diversidad cultural el derecho no puede ser homogéneo; de ahí que el derecho positivo en un país como el Perú o el resto de América Latina tambalea y entra en crisis (Tamayo Flores 1992). Como consecuencia, se agravan los conflictos sociales, ambientales, se expanden la drogadicción y la delincuencia en todos los rincones, porque precisamente en la práctica el derecho positivo es ineficaz y ante la diversidad cultural, se vuelve abstracto, inaplicable o puramente teórico, al ser escrito desde la posición eminentemente exótica dominante u occidental. En tanto que el derecho consuetudinario en sociedades indígenas, emerge y fluye a partir de las prácticas culturales, en función a los valores y principios de la colectividad, según el criterio de la dinámica cultural y según el proceso histórico en el que se desenvuelve la sociedad. Desde la doctrina del derecho positivo la tipificación de carácter de norma, el derecho consuetudinario es determinado a partir de dos criterios: a) uso repetitivo y generalizado b) conciencia de obligatoriedad (Bazán Cerdan 2008).

De hecho, las sociedades indígenas amazónicas que son tan diversas cultural y lingüísticamente no necesariamente se interesan en cosas teóricas o abstractas para tener que recurrir a leyes escritas y codificadas, sino que la inserción a la vida y a su mundo cultural es práctica y oral. Al ser práctica, es hacedora de su propio derecho de interés común o colectivo; y al ser oral, es dialogante entre las personas 
que se interrelacionan culturalmente, a través de las convivencias comunitarias, vinculándose unos a otros mediante la ayuda mutua entre parientes y relacionados culturalmente.

Stavenhagen e Iturralde (1990: 29-30) demarcan claramente la diferencia entre el derecho consuetudinario y el positivo, ligado al Estado:

Lo que caracteriza al derecho consuetudinario es precisamente que se trata de un conjunto de costumbres reconocidos y compartidos por una colectividad (comunidad, pueblo, grupo étnico), a diferencia de las leyes escritas que emanan de una autoridad política constituida y cuya aplicación está en manos de una autoridad, generalmente del Estado. La diferencia fundamental entonces, sería que el derecho positivo está vinculado al poder estatal, en tanto que el derecho consuetudinario es propio de sociedades que carecen de Estado, o simplemente operan sin referencia al Estado.

Luis Alberto Pacheco, al hacer un peritaje antropológico en la Amazonía sobre un homicidio ocurrido en la comunidad asháninka de Mayapo, describe claramente que los actos de robo son castigados drásticamente por los propios asháninkas bajo sus propios mecanismos de códigos culturales: son ordenados y ejecutados por las decisiones de la asamblea comunal. En ella, por acuerdo unánime, se decidió castigar ejemplarmente al ladrón. No encontraron mejor manera de hacerlo que aplicando la antigua costumbre nativa, como aún hoy se hace en las comunidades nativa de Kapitiri e Ivotsote: amarrar al autor del crimen al árbol conocido como "tangarana", donde habitan unas hormigas llamadas por los lugareños "perro negro" o "kuki". Estas hormigas de una longitud de aproximadamente cinco a siete centímetros de largo, son venenosas y, como es lógico, un ataque masivo de estas a un ser humano le asegura su muerte:

El niño infractor de la norma social falleció al día siguiente del castigo, luego de haber sido atacado por las hormigas antedichas por espacio de diez minutos. Por supuesto que antes de morir confesó su crimen y pidió disculpas. Durante su agonía no fue tratado médicamente, a pesar de haber sido posible. Su abuela y la comunidad lo dejaron morir, porque "si vive va a seguir robando" (Pacheco 2001: 140-1).

Pacheco interpreta este tipo de castigo en la sociedad asháninka a partir del materialismo histórico, como: "no es la conciencia del hombre la que determina su ser, sino, por el contrario, el ser social es lo que determina su conciencia" (al castigo o la muerte). Por otro lado, de la misma manera trata de recurrir a la cosmovisión amazónica como un modo de resolver el problema de robo desde la óptica de la cultura.

En mi permanencia de tres años en el pueblo asháninka, específicamente en el valle del Pichis, pude observar que al aplicar el castigo a los infractores de la norma colectivo o comunal, necesariamente el infractor tiene que sentir dolor (de esto hablaremos más adelante), sino, no es castigo. Asimismo, el castigo y el dolor 
son de diferentes grados y de acuerdo con el delito cometido. En este caso, el robo es uno de los delitos más graves, mal visto y no aceptado por todo los asháninkas; por lo tanto, el castigo debe ser severo. En todo caso, causar muerte al infractor no es un delito cuando prima la necesidad de deshacerse del mal elemento, evitando que pueda seguir infringiendo la ley asháninka. Además, robar es causar el desprestigio a toda la parentela consanguínea (Nosháninka) y a la descendencia de la sangre masculina. De ahí que "su familia lo deje morir".

Esto choca con la mirada del derecho positivo. Tal se aprecia en un estudio que revisa los pormenores de un juicio seguido a los comuneros involucrados en un linchamiento ocurrido en una comunidad campesina de Cusco. Al examinar cómo se aplicó el artículo 15 del Código Penal peruano sobre un error culturalmente condicionado, vemos que los operadores del derecho escrito se conciben y se posicionan como únicos personajes que pueden resolver y regular los conflictos a través del derecho escrito (Robin 2009).

El modo de resolución de conflictos empleado por los comuneros pampamarquinos llevó a juzgarlos como miembros de una sociedad congelada en el pasado. Los comuneros son acusados como salvajes por quienes muestran incapacidad absoluta de ubicarse en una alteridad cultural. De hecho, los comuneros que ejecutaron justicia habían actuado luego de haber recurrido ante las autoridades competentes del Estado, haciendo recurrentes denuncias por los constantes robos, líos ocurridos en la comunidad, y al no ser escuchados decidieron castigar acatando una decisión de la asamblea comunal. El proceso seguido previamente, según las reglas del derecho positivo, no les había servido para la solución del conflicto que los agobiaba. Pese a ello, los pampamarquinos fueron considerados salvajes, sujetos que vivían fuera de la nación peruana y recibieron la sentencia emitida en consecuencia:

[...] de parte de los representantes de la ley está la afirmación de que, por su cultura, los comuneros vivían fuera de la nación; mientras estos buscaban ser tomados en cuenta e incluidos en la sociedad peruana, como cualquier ciudadano, pero tropezaron con la arraigada imagen de "lo otro" que se les ofrecía en el espejo (Robin 2009: 95).

Sobre ese desfase entre la concepción de las autoridades del Estado y la decisión tomada por los comuneros, es inevitable hacerse algunas preguntas:

¿Estamos realmente frente a un modo ancestral de resolución de conflictos o nos enfrentamos más bien a una situación de cotidiana marginalidad y exclusión social que indujo el recurso de los comuneros a esa forma radical de ejercer la justicia por sus propias manos? [...]. Pero es necesario subrayar el hecho de que el linchamiento ocurrido en Pampamarca no corresponde a una norma jurídica asentada en la cultura de las comunidades serranas, sino que aparece, por lo menos parcialmente, como la consecuencia dramática de un vacío de poder, revelador de las fallas, ineficiencia y falta de responsabilidad de los órganos del Estado teóricamente encargado de administrar justicia (Robin 2009: 95-6). 
En esta interpretación, el acto de homicidio ocurrido fue como una señal de respuesta al Estado, al no ser escuchados por sus instancias de justicia. En este caso, Robin nos muestra el choque de derechos en comunidades indígenas, a partir de la ineficiencia del Estado, por un lado, y la discriminación, subordinación social y cultural de los operadores del derecho positivo del Estado hacia las comunidades indígenas, por otro lado.

Del Alcázar (2001) nos muestra otro caso relevante y revelador, cuando estudia la comunidad nativa de Shintuya que pertenece al grupo étnico harambukt. Se trata de situaciones de exclusión que recaen sobre mujeres que rompen la estructura sociocultural en contextos de pluralidad cultural: primero, al casarse con colonos; segundo, al aceptar ayuda de misioneros, como en el caso de una mujer indígena que con esa ayuda logró estudiar y ser maestra de bilingüe de una escuela de la comunidad de Shintuya; y tercero, por el solo hecho de ser mujeres, situación que les impide recibir chacras con las cuales asegurarse la subsistencia. Obviamente desde el derecho positivo occidental, el derecho consuetudinario no puede violar los derechos fundamentales de la persona. La exclusión hacia las mujeres, esto es la discriminación en razón de género, atenta contra al derecho constitucional y fundamentalmente afecta al principio de igualdad. Pues bien, a partir de esta concepción etnocéntrica se inicia el choque de visiones en concreto hacia el derecho, porque según la tradición o derecho consuetudinario de los harambut las mujeres casadas con colonos deben salir de la comunidad, debido a que la intromisión externa (presencia del colono o la propia educación occidental) rompe la estructura sociocultural de la etnia, en su propia visión. Dice Martin del Alcázar (2001) que la educación bilingüe con contenidos occidentales no es vista como algo que integra, sino que causa un alejamiento e imposición, esto explica la exclusión hacia la profesora de educación bilingüe. En cuanto a las mujeres que son excluidas de la chacra y privadas de un medio de subsistencia, no se llega determinar el motivo; solo de manera general encontramos una referencia en versión de Liliam Landeo:

Los hombres y las mujeres tienen diferentes perspectivas de la cultura y de la sociedad. Los Arakmbut tienen grupos patrilineales, todos los hijos de una pareja son del mismo grupo que el padre, no de la mujer. Para los varones es importante respetar las líneas de consanguinidad de donde deriva el parentesco y se refuerza la figura masculina. En cambio, para las mujeres es más importante la localidad (puede ser casa de marido, de su madre o de su padre) no interesa mucho la línea de consanguinidad, por lo tanto, no refuerza el grupo del parentesco. En este sentido la incorporación de un "elemento externo" (colono) rompe la estructura de parentesco para la conservación del clan; al mismo tiempo, la mujer es vista como alguien que rompe estructuras tradicionales dentro del grupo familiar y, si esto ocurre, la mujer debe salir de la comunidad (citado por Del Alcázar Chávez 2001: 186-187).

La versión del Liliam Landeo da pistas en cuanto a la exclusión de la chacra respecto a las mujeres. En muchas culturas, a las mujeres no se les suele conceder 
la tierra ni por herencia (Luque 2013), cuando la sociedad se estructura por líneas patrilineales como bien encontramos en la versión de Liliam Landeo: “Los harambukt tienen grupos patrilineales donde todos los hijos de una pareja son del mismo grupo que el padre, no de la mujer". En estas formas de organización social patrilineal no es que exista una exclusión y desvalorización propiamente dicha hacia las mujeres, sino que en el trasfondo cultural los criterios suelen ser complementarios, debido a que el matrimonio como norma suele ser endogámico, por lo tanto, la mujer pasa a pertenecer a la familia de su marido, mas ya no a la familia consanguínea de donde proviene. Por lo tanto, la mujer que se casa con un no indígena sale automáticamente de la comunidad. Con esto no pretendo afirmar que las sociedades endogámicas sean totalmente cerradas, sino, una mujer puede enamorarse con un no indígena, puede visitar las veces que sea necesario a la comunidad de donde proviene, pero si pierde el derecho de vivir en la comunidad. Por otro lado, esta forma de articularse y la supuesta exclusión hacia la mujer, mostrada por Martin del Alcázar, no es más que una respuesta a la colonización externa para generar una conciencia y a la vez la cohesión entre quienes están emparentados culturalmente en una estructura social, obviamente definida por normas que regulan la interacción social.

Aquí vemos cómo los modos de vida estructurados por los harambukt son distintos a los que sanciona el derecho occidental, tanto nacional como internacional sobre derechos humanos. En el proceso de occidentalización o intromisión externa, los más perjudicados o afectados son los pueblos indígenas que tienen otra manera de organizarse y de regular o entender el derecho.

Los estudios sobre el derecho en sociedades pluriculturales muestran diferentes formas de práctica. Cada cultura cuenta con su propio repertorio de derecho; pero, por otro lado, tenemos una sociedad dominante que es construida en función del etnocentrismo occidental individualista que, ante la diversidad de culturas, responde con antagonismo, confrontación y asimetría. Por último, cabe señalar que la creación de Estado-nación no ha servido para integrar y consolidar una auténtica República peruana con rostro multicultural y con visión inclusiva, en la que cada pueblo pueda ser entendido en sus propios términos o en el marco de la justicia intercultural emancipatoria.

La antropología jurídica establece que el derecho se origina con la organización de sociedades en hordas, familias, clanes (Maine 1980), cuya función es regular el orden y respeto entre quienes conforman la colectividad. Por lo tanto, el "derecho es un producto cultural formado gradualmente en la práctica de las relaciones jurídicas de cada pueblo, sin que el legislador intervenga como factor creador y generador, sino como un mero formalizador" (Herrera 1998: 09).

Peña Jumpa (1998: 57), al hacer un estudio sobre justicia comunal entre los aymaras de los Andes del Perú, afirma que "el derecho se presenta fundamentalmente de modo material o práctico. Es decir, el derecho se expresa más que todo a través de reglas o normas, que son muy concretas o tangibles para los individuos del 
grupo; se presenta como un instrumento útil para la convivencia del grupo social". De la misma manera, afirma que hay un derecho vivo, que brota del pueblo: "Es necesario que se conozca y acepte, desde el Estado oficial, que en comunidades campesinas como Calahuyo (aymara) existe otra concepción de derecho, otro orden jurídico, y que todo ello se ve reflejado en la presencia de órganos, procedimientos y racionalidad propias, para resolución de sus conflictos" (op. cit.: 332).

\section{Conclusiones}

Los jefes de las comunidades han aprendido a moverse en ambos lados de la realidad nacional: por un lado, el Perú profundo, indígena; y, por otro lado, el Perú oficial colonial que no entiende al Perú indígena de miles de años de civilización. Así mismo, las autoridades de las comunidades se mueven en función a su escenario cultural y lingüístico, en función de lo que vive y dice su gente; es decir, de un modo de andar o vivir, pensar y sentir propio.

Las sociedades, sean indígenas o no indígenas, siempre están sujetas a una ley. En las sociedades indígenas, la ley opera de manera automática, nace o se origina de las mismas prácticas socioculturales y políticas, mientras que en sociedades no indígenas la ley es impuesta por las instancias de la clase político-burocrática del Estado, por lo tanto, no es producto de las prácticas socioculturales de la colectividad específica.

Desde las instancias de las autoridades estatales formadas en la lógica etnocéntrica occidental, la ignorancia acerca de la ley indígena es generalizada. Precisamente, en las sociedades indígenas asháninka pesan dos criterios en el ineludible cumplimiento de la ley: el criterio sociocultural y el criterio políticocomunal. 


\section{Bibliografía}

Albó, Xavier

2000 Derecho consuetudinario: posibilidades y límites. Colección IECTA, N. ${ }^{\circ} 18$.

Bazán Cerdan, F.

2008 Estado del arte del derecho consuetudinario: el caso del Perú. Lima: Serie de investigaciones del programa de acceso a la justicia en comunidades rurales- PROJUR.

Belaunde, E. L., Coronado, H., \& Otros.

2005 Ciudadanía y cultura política entre los Awajún, Asháninka y Shipibo-Conibo de la Amazonia Peruana. Lima: CAAAP.

Brandt, Hans-Jürgen

1986 Justicia popular. Nativos y Campesinos. Lima: Fundación Friedrich Naumann.

Calderón Pacheco, Luis

2003 "Relaciones interétnicas entre mestizos y nativos kechwa en Lamas en el contexto de la globalización". En: Carlos Iván Degregori (editor), Comunidades Locales y Transnacionales. Cinco estudios de caso en el Perú. Lima: IEP.

Castillo Gallardo, Mayarí

2009 "Pueblos indígenas y derecho consuetudinario. Un debate sobre las teorías del multiculturalismo". En: Nueva Antropología [online], vol. 22, N. ${ }^{\circ} 71$, pp.13-29. En: http://www.scielo.org.mx/pdf/na/v22n71/v22n71a2.pdf.

De Sousa Santos, Boaventura

2012 Derecho y Emancipación. Quito: CEDEC.

Del Alcázar, Martín

2001 "Multiculturalismo, género y derechos humanos. El caso de la Comunidad Nativa de Shintuya". En: BIRA/ Boletín Instituto Riva-Agüero N. ${ }^{\circ} 28$. Lima: Pontificia Universidad Católica del Perú.

Descola, Philippe

2004 "Las cosmologías indígenas de la Amazonía" En: Alexandre Surrallés y Pedro García Hierro (Editores). Tierra Adentro. Territorio Indígena y Percepción del Entorno. Lima: IWGIA.

García Hierro, Pedro

2004 Territorios indígena: tocando a las puertas del derecho. En: Surrallés y García H.

Tierra adentro. territorio indígena y percepción del entorno. Lima: IWGIA. 
Gray, Andrew

1984 "Los amarakaeri: una noción de estructura social" En: Amazonía Peruana $\mathrm{N}^{\circ}$ 10. Volumen V. Lima: CAAAP.

Herrera, Enrique

1998 Práctica metodológica de la investigación jurídica. Buenos Aires: Astria.

Konstantinov, F.V.

1963 El materialismo histórico. México: Grijalbo S.A.

Krotz, Esteban

2002 Antropología jurídica: perspectivas socioculturales en el estudio del derecho. Iztapalapa-México: Universidad Autónoma Metropolitana Iztapalapa.

Luque Chuquija, Euclides

2013 El derecho de sucesión de la propiedad de la tierra en la parcialidad campesina de Santiaguillo (Puno). Tesis para optar el Grado Magíster en Antropología, mención en Antropología Andina. Lima: Universidad Nacional de Mayor de San Marcos.

Marés, Frederico

2014 "¿Antropología o derecho?: crítica a la autosuficiencia del derecho". En: Milka Castro Lucic (Editora), Los Puentes entre la Antropología y el Derecho. Orientaciones desde la Antropología Jurídica. Santiago: Programa de Antropología Jurídica e Interculturalidad, Facultad de Derecho, Universidad de Chile.

Pacheco, L. A.

2001 Las penas "salvajes" en el ejercicio de la función jurisdiccional de las Comunidades Nativas en el Perú (motivación para la discusión sobre la jurisdicción especial desde una visión del materialismo histórico). BIRA/Boletín Instituto Riva-Agüero N. ${ }^{\circ}$ 28. Pontificia Universidad Católica del Perú.

Peña Jumpa, A.

1998 Justicia comunal en los andes del Perú en caso del Calahuyo Huancané. Lima: PUCP.

Radcliffe-Brown, A. R.

1994 "Sobre la estructura Social", En: Paul Bohannan y Mark Glazer (Editores), pp. 315-327. Antropologia, Lecturas. Madrid: McGraw-Hill.

Robin Azevedo, V.

2009 "Linchamientos y legislación penal sobre la diferencia cultural. Reflexiones a partir de un juicio por homicidio contra unos comuneros del Cusco". En: Valerie Robin Azevedo y Carmen Salazar-soler (editoras), El regreso de lo indígena. Lima: IFEA. 
Rojas Zolezzi, Enrique

2014 El morral de colibrí. Mitología, chamanismo y ecología simbólica entre los asháninkas del oriente peruano. Lima: Horizonte.

Sahlins, Marshall

1983 Economía de la edad de piedra. Madrid: AKAL.

Sánchez Botero, Esther

2014 "Algunos Presupuestos Epistemológicos y Metodología de la Antropología Jurídica". En: Milka Castro Lucic (editora). Los puentes entre la Antropología y el Derecho. Orientaciones desde la Antropología Jurídica. Santiago de Chile: Universidad de Chile. Facultad de Derecho.

Sánchez Botero, Esther

2010 El peritaje antropológico, Justicia en clave cultural. Bogotá- Colombia: GTZ.

Santos, B. d.

2012 Derecho y emancipación. Quito: CEDEC.

Stavenhagen, Rodolfo. \& Iturralde, Diego

1990 Entre la ley y la costumbre. El derecho consuetudinario indígena en América Latina. México: Instituto Indigenista Interamericano/Instituto de Derechos Humanos.

Tamayo Flores, Ana María

1992 Derecho en los andes. Un estudio de antropología jurídica. Lima: CEPAR.

Tamayo Herrera, José

1998 Liberalismo, indigenismo y violencia en los países andinos (1850-1995). Lima:

Universidad de Lima.

Tubino, Fidel

2015 La interculturalidad en cuestión. Lima: Pontificia Universidad Católica del Perú.

1973 Varese, Stefano La Sal de los Cerros: una aproximación del mundo Campa. Lima: Retablo de Papel.

Varela, R.

2002 "Naturaleza/cultura, poder/política, autoridad/legitimidad". En: Esteban Krotz (Ed.) Antropología jurídica: perspectivas socioculturales en el estudio del derecho. Iztapalapa-México: Universidad Autónoma Metropolitana Iztapalapa.

Yrigoyen, Raquel

2001 Retos para construir una juridicidad pluricultural (balance de los proyectos de la ley sobre el art. 149 de la Constitución). En BIRA/ Boletín Instituto Riva-Agüero No 28. Lima: Pontificia Universidad Católica del Perú. 